\title{
Bodily self-relatedness in vicarious touch is reflected at early cortical processing stages
}

Julia Adler ${ }^{1}$ and Helge Gillmeister ${ }^{2}$

${ }^{1}$ Department of Psychosomatic Medicine and Psychotherapy, University Medical Center Mainz, Germany

${ }^{2}$ Department of Psychology, University of Essex, Colchester, UK

Corresponding author:

Helge Gillmeister

Department of Psychology

University of Essex

Wivenhoe Park

Colchester $\mathrm{CO} 3$ 3DX

E-Mail: helge@essex.ac.uk 


\section{Abstract}

Studies have suggested that there is a strong link between the bodily self and the mechanisms underlying vicarious representations. Here we used somatosensory event-related potentials (ERPs) to investigate the temporal dynamics of vicarious touch for stimuli that are more or less related to one's own body (human hands vs. rubber gloves). We found that vicarious touch effects were restricted to self-relatable events (human hands) at early, implicit stages of somatosensory processing (P45). At later, more cognitive stages of processing (late positive complex, LPC), the vicarious touch effect was stronger for selfrelatable events (touch on human hands) than non-self-relatable events (touch on rubber gloves), but present for both. Both effects, but especially the vicarious touch effect for human hands at P45, were stronger in individuals with higher levels of interoceptive awareness. Our results confirm that there is a tight link between vicarious touch and the bodily self, and characterise P45 effects of vicarious touch as its likely neural basis. We propose that vicarious processes and the embodied self may be representationally indistinct (linked in a common neural representation) at early, implicit somatosensory processing stages.

Key words: somatosensory, ERPs, vicarious touch, mirror touch, embodied self, interoceptive awareness, P45, self-other distinction 


\section{Introduction}

Vicarious touch ('mirror touch') is the automatic simulation of touch observed on another person's body. It is linked to the activation of a broad somatosensory cortical network during the visual perception of tactile sensations (for reviews see Gillmeister, Bowling, Rigato, \& Banissy, 2017; Keysers, Kaas, \& Gazzola, 2010). From a developmental perspective, early imitative (mirroring) experiences involving multiple bodily senses enable both the motoric and the emotional attunement between infants and their primary caregivers, which is thought to be crucial for the emergence of our basic bodily sense of self (e.g., Gallese \& Sinigaglia, 2010; Legrand, 2006; Rochat \& Striano, 2000; see also Blanke, Slater, \& Serino, 2015). This basic sense of self is the foundation for the developing ability to represent ourselves (and others) as mental agents ("mentalising") (e.g. Fonagy, Gergely, \& Target, 2007; see also Markova \& Legerstee, 2006; Stern, 1995). In other words, our social being is based on mirroring - an intuitive bodily resonance with others (Fuchs \& Koch, 2014; Merleau-Ponty, 1962).

Given its developmental origins, it seems fitting that the neurophysiological underpinnings of vicarious experiences lie in the sensorimotor systems related to matching externally perceived (e.g. visual) and internally experienced (sensorimotor, affective) events (the broader mirror neuron system; see Molenberghs, Cunnington, \& Mattingley, 2012). Indeed, fMRI studies have shown that the visual observation of touch gives rise, not only to activity in somatosensory cortices (SI and SII), but also to associated activity in frontoparietal mirroring networks, self-other distinction networks, and insula 
(see Bufalari \& Ionta, 2013; Gillmeister et al., 2017; Keysers et al., 2010 for reviews).

In line with the developmental view that mirroring shapes the sense of self, vicarious touch in adults results in stronger behavioural responses when there is greater self-relatedness (Cardini, Costantini, Galati, Romani, Làdavas et al., 2011; Cardini, Tajadura-Jimenez, Serino, \& Tsakiris, 2013; Serino, Pizzoferrato, \& Làdavas, 2008; Serino, Giovagnoli, \& Làdavas, 2009), as well as in earlier ERP effects when viewing touch on one's own face compared to that of another person (Adler, Schabinger, Michal, Beutel, \& Gillmeister, 2016). Self-relatedness can be experienced for stimuli that are associated with one's own self, or specifically with one's own body (e.g. one's own face vs. face of another person) or for stimuli that are more "like" one's one body (e.g. a human face vs. an inanimate object).

An additional route to experiencing self-relatedness lies within the observer himself, that is, how closely attached to their own body a person feels (the embodied self). An example of a psychological condition that is characterised by a lack of such an attachment is depersonalisation (e.g. Simeon, 2004). The disrupted relationship with one's own bodily self is expressed as, for example, feeling detached from body parts or the whole body, looking in the mirror and feeling estranged from one's image, and not feeling in control of one's movements (e.g. Sierra, Baker, Medford, \& David, 2005; Sierra \& Berrios, 2000; Sierra \& David, 2011; Simeon, 2004). Depersonalisation occurs not only in mental illness, but can also be found as temporary symptoms within the general population, for example following severe stress or trauma (e.g. Charbonneau \& O'Connor, 1999; Simeon, 2004; Trueman, 1984). 
It could be argued that the strength of the individual's attachment to their bodily self drives the degree to which external stimuli are experienced as self-related. This entails that a weaker attachment to one's bodily self (e.g., in depersonalisation) should be associated with experiencing external stimuli (e.g., seeing one's own face) as less self-related. We showed this in our earlier study (Adler et al., 2016), where we used ERPs to measure the time course of vicarious touch while participants observed their own and others' faces. Vicarious touch effects were present at an early somatosensory cortical processing stage (P45) but only when observing one's own face. Importantly, this effect was absent for individuals who reported frequently feeling detached from their own body and self (symptoms of depersonalisation). In contrast to the P45, later, more cognitive ERP components (P200), were less selectively associated with the degree of self-relatedness. While early and late processes may work together to enable the interaction between visual and tactile bodily information, our findings suggest that P45 is the most specific index of bodily self-relatedness in vicarious touch that can be measured with ERPs to mechanical tactile stimuli.

Other findings within the literature appear to fit well with this idea. Effects of vicarious touch at P45 have been shown in study designs likely to elicit feelings of self-relatedness by showing touch on hands seen in a first-person perspective (Bufalari, Aprile, Avenanti, Di Russo, \& Aglioti, 2007; Martinez-Jauand, Gonzalez-Roldan, Munoz, Sitges, Cifre et al., 2012; Deschrijver et al., 2015). Since P45 is likely to reflect neural activity in S1 (Allison, McCarthy, Wood, Williamson, \& Spencer, 1989; Allison, McCarthy \& Wood, 1992; Schubert, Ritter, Wüstenberg, Preuschof, Curio et al., 2008), it is no surprise that SI is itself 
modulated by vicarious touch (e.g. Blakemore, Bristow, Bird, Frith, \& Ward, 2005; see Keysers et al., 2010 for a review). Vicarious touch in SI is strongly affected by the perspective of the viewed hand (Schaefer, Xu, Flor, \& Cohen, 2009; Schaefer, Heinze \& Rotte, 2012), and in line with this, a recent study (Rigato, Bremner, Gillmeister, \& Banissy, 2019) also reports that the perspective of the viewed hand modulates vicarious touch responses over P45.

The present study aimed to substantiate the idea that vicarious touch effects at P45 are a neuronal index of bodily self-relatedness. To this end we aimed to extend our previous findings by investigating the time course of cortical vicarious touch effects in response to stimuli differing in self-relatedness (touch on human hands vs. rubber gloves), and in relation to observers' individual levels of interoceptive abilities and mentalising. Interoception is the awareness of our internal, physiological processes, such as our heartbeat (Craig, 2002). Individual levels of this ability are positively related to own body-awareness (Tsakiris, Tajadura-Jimenez, \& Costantini, 2011), negatively related to feeling dissociated from one's body (Mehling, Price, Daubenmier, Acree, Bartmess et al., 2012), and may thus be an indication of the strength of the second route to experiencing self-relatedness (the embodied self). Further, one might argue that both a stronger sense of bodily self and stronger mentalising abilities are associated with stronger vicarious representations. This is because mirroring interactions during early childhood are not only crucial for the development of the basic sense of bodily self, but also enable an affective reciprocity between infants and caregivers, which is thought to be the basis for mentalising (e.g., Fonagy et al., 2007). In line with this, vicarious representations in S1 / at P45 have previously also been associated with individual levels of empathy, specifically with perspective-taking (Bolognini, Rossetti, Convento, \& Vallar, 2013; Bolognini, 
Rossetti, Fusaro, Vallar, \& Miniussi, 2014; Gazzola, Aziz-Zadeh, \& Keysers, 2006; Martinez-Jauand et al., 2012; Schaefer et al., 2012).

Therefore, the strongest self-relatedness in the present study can be assumed during the observation of touch on a human hand (vs. rubber gloves) in observers who have better interoceptive and mentalising abilities (vs. weaker abilities). Thus, we expected the strongest effects of vicarious touch at early processing stages (P45) for these viewing conditions and individuals. In addition to these early processes, we expected further, less selective effects at later, cognitive components (late positive complex, LPC, including P200, P300 and subsequent waveforms). Since these components reflect a variety of different operations, we may expect effects of self-relatedness (see Adler et al., 2016; Deschrijver, Wiersema, \& Brass, 2015) or self-other distinction (Longo, Musil, \& Haggard, 2012; Knyazev, 2013), as well as more general congruency effects due to the mismatch between visual and tactile stimulation (see Deschrijver et al., 2015; Kok, 2001; Polich, 2007).

Similar to Adler et al. (2016), we used the tactile mirroring paradigm, where observers receive tactile stimuli on their own, hidden body while viewing another person's body being touched or not touched at the same time. As mirroring entails an internal simulation of the observed event, a match between the representations of the felt and the seen stimulus should be present when viewing touch but not when viewing no touch. Thus, vicarious touch effects are defined as differences in somatosensory processing between touch and no-touch conditions. 


\section{Method}

\subsection{Participants}

The sample consisted of 46 healthy adults ( 21 men; 1 left-handed) with a mean age of 23.3 years (SD: 5.7 years). All had normal or corrected-to-normal vision. The study was conducted at the University of Essex in accordance with the 2008 Declaration of Helsinki and approved by the Department of Psychology Ethics Committee. Informed written consent was obtained from each participant prior to testing.

\section{2. Materials and Apparatus}

For the ERP task, we presented visual stimuli (grey-scaled images of human hands or rubber gloves, see Figure 1 ), which measured $6.1^{\circ}$ of horizontal and $3.4^{\circ}$ of vertical visual angle and were presented against a white background in the centre of a computer screen. Mean luminosity of the images was adjusted to match across stimulus categories. A rubber glove was chosen for its low-level visual similarity with human hands, with the open end of the glove clearly visible to ensure that participants could be certain that the glove was not worn by a human hand.

Neutral images showed a left or right human hand or rubber glove in a prone position with a pencil above it (see Figure 1). Touch images showed the pencil lower down, depressing the first dorsal interosseous (FDI) muscle of the human hand (Figure 1, upper timeline) or the equivalent location of the rubber hand (Figure 1, lower timeline). No-touch images showed the pencil next to the hand, 
in a position chosen so that the perceived distance travelled by the pencil would be similar across touch and no-touch trials.

Figure 1 here

A tactile controller (Heijo Research Electronics, London, UK) and mechanical solenoid stimulators (M\&E Solve, Rochester, Kent, UK) delivered suprathreshold taps by pushing a blunt plastic tip against the participant's skin whenever a current was passed through the solenoid. Taps were delivered to the FDI muscle of the participants' left or right hand during the presentation of each touch or no-touch image. White noise was played through in-ear headphones to mask solenoid sounds.

Additionally, we investigated perspective taking / mentalising abilities and interoception in four different tasks. We used one perspective taking self-report survey and one mentalising task, one task of interoceptive sensitivity, and one self-report survey of interoceptive awareness.

The perspective taking survey was the perspective-taking subscale of the Interpersonal Reactivity Index (IRI, Davis, 1983), previously used to demonstrate links between empathy and vicarious representations including touch (Bolognini et al., 2013, 2014; Gazzola et al., 2006; Schaefer et al., 2012). This subscale consisted of seven statements such as "I sometimes try to understand my friends better by imagining how things look from their perspective", scored on a 6-point Likert scale from 0 (Does not describe me well) 
to 5 (Describes me very well). All scores were added to compute each person's perspective-taking score (0 to 35$)$.

The mentalising task was a theory of mind (ToM) task (Kinderman, Dunbar, \& Bentall, 1998; Rutherford, 2004). Participants were asked to carefully read three complex social scenarios, the understanding of which required participants to take the described people's perspective. The scenarios were chosen from among the four multiply embedded false belief problems used by Rutherford (2004). After reading each scenario, and without looking at the text again, participants were asked to indicate which of two slightly different statements about the scenario was true. There were 5 pairs of statements. Four of these were theory of mind statements, requiring the participant to represent up to four nested levels of representations of the mental contents of the people described (e.g., the $4^{\text {th }}$-order statement "Simon hoped Jim would believe that Susan thought Edward wanted to (vs. did not want to) marry Betty"). The remaining statement pair was a $4^{\text {th }}$-order nested non-ToM question, which did not require mentalising to assess the contribution of general understanding and memory of embedded relationships on performance (e.g., "The girl whose car Simon works on practices dance with the person who is a loan officer (vs. computer consultant) in Edward's bank"). One of the scenarios contained an additional $3^{\text {rd }}$-order ToM question (see Rutherford, 2004). Accuracy at each of the four levels of mentalising was computed for each scenario and then averaged across the scenarios ( 0 to 1 ). Accuracy for to the $4^{\text {th }}$-order non-ToM questions was also computed in this way ( 0 to 1 ).

To measure interoceptive sensitivity, we used a heartbeat counting task (Schandry, 1981). Participants silently counted their heartbeat in 30-second intervals, while a small pulse oximeter attached to the index finger of their left 
hand and shielded from view monitored the blood oxygen concentration and changes in blood volume in the skin (photoplethysmography), and displayed the participant's pulse (heartbeats per minute) in real time. Our measure of interoceptive sensitivity was the difference between participant-reported and oximeter-based scores, averaged across two instances of the counting task to obtain a more robust estimate (e.g., Wittkamp, Bertsch, Vögele, \& Schulz, 2018).

Finally, to test interoceptive awareness, participants completed the Multidimensional Assessment of Interoceptive Awareness (MAIA; Mehling et al., 2012), comprising of a 32-item list of statements such as "I listen for information from my body about my emotional state", scored on a 6-point Likert scale ranging from 0 (This never applies to me on a daily basis) to 5 (This always applies to me on a daily basis). The MAIA assesses interoceptive awareness across eight dimensions: noticing, not-distracting, not-worrying, attention regulation, emotion awareness, self-regulation, body listening, and trusting. These eight dimensions are sorted into five separate categories (see Table 1). Scores for all statements pertaining to each of the eight dimension were averaged ( 0 to 5 ).

Table 1 here

\section{3. Procedure}

Before the EEG task, participants completed two instances of the heartbeat counting task, one at the start of the session, and one after 
completing all other questionnaires. They were instructed to close their eyes, focus inward and on their own heartbeats. They were asked to count their heartbeats in a time period defined by two beeps from a timer, one at the start of the interval and one at the end. The experimenter noted down all pulse values that were measured during the counting interval (30 seconds), which were averaged after the experiment. The number of heartbeats reported by the participant was doubled to convert it to beats-per-minute for each 30 -second interval and subtracted from the measured pulse (absolute rather than signed difference) to obtain the counting error. The counting error was divided by the pulse to obtain a heartbeat perception score between 0 and 1 , and this score was averaged across the two instances of the heartbeat counting tasks as a measure of interoceptive sensitivity (see e.g. Pollatos et al., 2008).

Between the two heartbeat counting tasks, participants completed the IRI perspective-taking subscale, the MAIA and the ToM task.

For the EEG task, participants were told to observe the visual stimuli carefully, focusing on the part of the hand that may be touched, and to silently count any double touches they saw, regardless of whether they were delivered to the human hand or to the rubber glove. The counting task was used to ensure that participants attended to the visual stimuli. They were also told that they could ignore felt taps on their own hands as these were irrelevant to the counting task.

As shown in Figure 1, each experimental trial started with the neutral stimulus (hand with pencil above it) for 1000 ms. Then, the touch or no-touch stimulus appeared for $200 \mathrm{~ms}$, accompanied by a $200-\mathrm{ms}$ tap to the participant's hand. This was followed by the neutral stimulus again for $800 \mathrm{~ms}$, giving the 
visual impression of brief pencil movement to touch the hand (touch), or the surface next to the hand (no-touch). Between trials (ITI), a blank screen was shown for a random interval between 500 and 1000 ms.

In counting trials (double touch; not shown in Figure 1), we presented the visual touch or no-touch stimulus twice (e.g. $200 \mathrm{~ms}$ touch, $100 \mathrm{~ms}$ neutral, $200 m$ s touch, $800 m s$ neutral), giving the visual impression of two brief pencil movements to touch the hand. Only the second visual touch or no-touch stimulus was accompanied by the tactile stimulus.

There were 7 blocks of 60 trials, consisting of 48 experimental trials and 12 drawn from a list containing both experimental and counting trials, such that counting trials could be any number up to 12 per block. Half of all trials showed a human hand, and the other half a rubber glove; half showed touch stimuli, the other half showed no-touch stimuli. Half of the images showed touch on the left hand, the other half showed touch on the right hand, and half were accompanied by felt touch on the same hand as the viewed hand, while the other half were accompanied by felt touch on the other hand (see Adler et al., 2016). This was done to control specular and anatomical congruency between viewed and felt touch, as the literature on bimodal visual-tactile neurons in monkey parietal cortex (e.g. Ishida, Nakajima, Inase, \& Murata, 2010) and on mirror-touch synaesthesia (e.g. Banissy \& Ward, 2013) has reported both specular and anatomical (as well as bilateral or central) matching between viewed and felt touch. Therefore, each participant saw at least 84 trials of each critical condition, that is, each combination of viewed hand (human hand or rubber glove) and touch (touch or no touch stimuli) (see ERP analysis). All trial types were presented in equal proportions and in random order. 
Between blocks, participants received feedback about the accuracy of their counting, and were encouraged to pay better attention if necessary.

2. 4. EEG recording, ERP analysis and correlations

EEG was recorded with BrainVision actiCHamp from FP1, TP9, TP10, FC5, FC3, FC1, FCz, FC2, FC4, FC6, C5, C3, C1, CZ, C2, C4, C6, CP5, CP3, CP1, CPZ, CP2, CP4, and CP6 (subset of the international 10-10 system), using actiCAP active scalp electrodes (BrainProducts $\mathrm{GmbH}$, Gilching, Germany). This subset of electrodes were selected on the basis of the expected cortical distribution of somatosensory components over sensorimotor and anterior parietal cortices. EEG was amplified, band-pass filtered at $0.01-100 \mathrm{~Hz}$, and digitised at $500 \mathrm{~Hz}$. Off-line pre-processing of EEG signals was done using BrainVision Analyzer 2 (BrainProducts $\mathrm{GmbH}$, Gilching, Germany). Signals were filtered with a low-pass Butterworth filter of $30 \mathrm{~Hz}$ (12 dB slope), referenced to the average of the mastoids (TP9 and TP10), epoched for a period from $100 \mathrm{~ms}$ before to $400 \mathrm{~ms}$ after the onset of the tactile stimulus, and baseline-corrected using the $100-\mathrm{ms}$ window preceding stimulus onset. Trials with eye blinks or other artefacts (ie., a voltage exceeding $\pm 100 \mu \mathrm{V}$ at any electrode relative to the 100 -ms pre-stimulus baseline) measured in this interval were excluded from analysis ( $5 \%$ of trials for each critical condition on average; see below).

ERPs to tactile stimuli were averaged for all combinations of observed touch (touch vs. no-touch) and observed hand (human hand vs. rubber glove), collapsing over left and right touched and viewed hand conditions per hemisphere. This is, we collapsed over left and right hand touched hands by re- 
coding electrodes as either contralateral (electrode over hemisphere contralateral to the touched hand, regardless of viewed hand) or ipsilateral (electrodes over hemisphere ipsilateral to the touched hand, regardless of viewed hand). ERP mean amplitudes were computed for measurement windows over contralateral somatosensory component P45 (35-55 ms post-stimulus onset) and the bilateral frontocentral late positive complex (LPC, 220-380 ms). Measurement windows were selected on the basis of grandaveraged ERPs collapsed over all experimental conditions, and were centred around the peak of the P45 and the descending flank of the P200 (LPC). Within these measurement windows statistical analyses of ERP mean amplitudes were conducted for lateral somatosensory cortical electrodes FC3/4, FC5/6, C3/4, C5/6, CP3/4, and CP5/6, contralaterally for contralateral component P45 and bilaterally for the LPC. These electrodes were chosen because the grand averaged waveform collapsed over all conditions showed somatosensory components to be present and maximal here, relative to more medial sites (see also Figure 2 for voltage maxima in P45 and LPC time windows). Similar electrode selections can be found in other ERP studies of vicarious touch (e.g., Adler et al., 2016; Bufalari et al., 2007; Martinez-Jauand et al., 2012; Rigato et al., 2019).

Effects of touch observation and stimulus category were tested with repeated-measures ANOVAs for the within-subject factors observed touch (touch vs. no-touch), observed hand (human hand vs. rubber glove), and electrode (see above) for contralateral component P45. ANOVAs for bilateral LPC included the additional within-subject factor hemisphere (contralateral vs. ipsilateral). Greenhouse-Geisser corrections to the degrees of freedom were applied where appropriate. 
Bayesian probabilities associated with the occurrence of the null hypothesis $\left(H_{0} \mid D\right)$ and the experimental hypothesis $\left(H_{1} \mid D\right)$ were calculated alongside standard statistics to allow for clearer inferences about the probabilities of both significant and nonsignificant effects in our data (see Masson, 2011). These probabilities range from 0 (no evidence) to 1 (very strong evidence for null or experimental hypothesis).

Relationships between somatosensory ERP effects of touch observation, perspective-taking / mentalising and interoception were tested with Pearson's correlations. Correction for multiple correlations was applied using the method described by Benjamini \& Hochberg (1995), which controls the false discovery rate.

\section{Results}

During the EEG task, participants missed between 0 and 1 of the double touches per block on average (mean: $0.22, S D: 0.28$ ), showing that they paid sufficient attention to the visual stimuli.

\section{1. Somatosensory ERPs}

Figure 3 below shows somatosensory ERPs to touch on the hand when viewing touch and no touch images of human hands and rubber gloves over contralateral and ipsilateral electrodes. Vicarious touch can be defined as a voltage difference between touch and no touch observation conditions. It can be seen that there were effects of vicarious touch over P45 and the LPC (see Figure 2 for a 
comparison of the scalp distributions of the components and the effects of vicarious touch). Over P45, viewing touch on a human hand gave rise to a greater positivity compared to viewing no touch. This P45 effect of vicarious touch was absent when a rubber glove was viewed. Viewing touch also gave rise to smaller LPCs than viewing no touch and this difference appeared more pronounced when viewing human hands than rubber gloves.

Figure 2 here

Figure 3 here

These observations were confirmed in ANOVAs for early and late components. For P45 there was a significant two-way interaction between observed touch and observed hand $\left(F(1,45)=8.4, p=.006\right.$, partial $\eta^{2}=.16$, $\left.p\left(\mathrm{H}_{1} \mid \mathrm{D}\right)>.88\right)$, regardless of electrode $\left(F(5,225)=1.1, p=.362\right.$, partial $\eta^{2}=$ $\left..02, p\left(H_{0} \mid D\right)>.99\right)$. Follow-up ANOVAs for each level of observed hand showed that differences between touch condition and no-touch condition were present for human hands $\left(F(1,45)=9.8, p=.003\right.$, partial $\left.\eta^{2}=.18, p\left(H_{1} \mid D\right)>.93\right)$, but not for rubber gloves $\left(F(1,45)<1, p=.363\right.$, partial $\left.\eta^{2}=.02, p\left(\mathrm{H}_{0} \mid \mathrm{D}\right)>.82\right)$. Comparing the two observed hand conditions (human hand vs. rubber glove) in follow-up ANOVAs, we found that differences between human hands and rubber 
gloves were present when touch was observed $(F(1,45)=5.4, p=.025$, partial $\left.\eta^{2}=.11, p\left(H_{1} \mid D\right)>.65\right)$, but not for the no touch condition $(F(1,45)=1.7, p=$ .194 , partial $\left.\eta^{2}=.04, p\left(H_{0} \mid D\right)>.74\right)$. There were no other significant interactions with observed touch in these analyses. There were also no main effects of observed touch $\left(F(1,45)=2.0, p=.164\right.$, partial $\eta^{2}=.04, p\left(H_{0} \mid D\right)>$ $.71)$ or observed hand $\left(F(1,45)<1, p=.420\right.$, partial $\left.\eta^{2}=.02, p\left(\mathrm{H}_{0} \mid \mathrm{D}\right)>.82\right)$.

Altogether this shows that there were vicarious touch effects at early, implicit stages of somatosensory processing, shown as larger P45 amplitudes during the visual observation of touch relative to no touch. This P45 vicarious touch effect was restricted to human hands; it did not occur when a visually similar object (rubber glove) was touched. The vicarious representation is likely to be associated with a neuronal enhancement of tactile processing during the touch condition, specifically. This is because closer inspection showed that the touch condition, but not the no-touch condition, contained evidence of an enhancement of P45 amplitudes for the observation of human hands compared to rubber gloves.

For the LPC, similar to the P45, the interaction between observed touch and observed hand was significant $\left(F(1,45)=8.3, p=.006\right.$, partial $\eta^{2}=.16$, $\left.p\left(H_{1} \mid D\right)>.87\right)$, suggesting that vicarious touch effects in this time range were sensitive to whether human hands or rubber gloves were viewed, with stronger effects for human hands than rubber gloves. Follow-up ANOVAs for each level of observed hand showed that effects of observed touch were present for both human hands $\left(F(1,45)=54.5, p<.001\right.$, partial $\left.\eta^{2}=.55, p\left(H_{1} \mid D\right)>.99\right)$ and rubber gloves $\left(F(1,45)=22.1, p<.001\right.$, partial $\left.\eta^{2}=.33, p\left(H_{1} \mid D\right)>.99\right)$. For human hands, there was also a significant interaction between observed touch 
and electrode $\left(F(5,225)=20.0, p<.001\right.$, partial $\left.\eta^{2}=.31, \mathrm{p}\left(\mathrm{H}_{1} \mid \mathrm{D}\right)>.99\right)$. Pairwise comparisons of the estimated marginal means of the factor observed touch at all levels of electrode revealed that there were significant effects of observed touch at all electrodes $\left(F(1,45)>38.0, p<.001\right.$, partial $\left.\eta^{2}>.45\right)$.

For rubber gloves, there were significant interactions between observed touch and electrode, observed touch and hemisphere, and observed touch, hemisphere and electrode $\left(F(5,225)>3.1, p<.014\right.$, partial $\eta^{2}>.06$, $p\left(H_{1} \mid D\right)>$.99). Pairwise comparisons of the estimated marginal means of the factor observed touch at all levels of hemisphere and electrode revealed that there were significant effects of observed touch at all electrodes $(F(1,45)>8.9$, $p<.007$, partial $\left.\eta^{2}>.15\right)$.

Comparing the two observed hand conditions (human hand versus rubber glove) in follow-up ANOVAs, we found that differences between human hands and rubber gloves were present when touch was observed $(F(1,45)=12.6, p=$ .001 , partial $\left.\eta^{2}=.22, \mathrm{p}\left(\mathrm{H}_{1} \mid \mathrm{D}\right)>.65\right)$, but not for the no touch condition $(F(1,45)$ $<1, p=.737$, partial $\left.\eta^{2}<.01, \mathrm{p}\left(\mathrm{H}_{0} \mid \mathrm{D}\right)>.86\right)^{1}$.

In addition, the overall analysis of the LPC showed significant main effects of both observed touch $\left(F(1,45)=44.4, p<.001\right.$, partial $\eta^{2}=.50$, $\left.\mathrm{p}\left(\mathrm{H}_{1} \mid \mathrm{D}\right)>.99\right)$ and observed hand $\left(F(1,45)=4.6, p=.037\right.$, partial $\eta^{2}=.09$, $\left.p\left(H_{1} \mid D\right)>.58\right)$. This reflected the findings that touch on observers' hands evoked greater negativities when viewing touch than no touch in this time range, and

\footnotetext{
${ }^{1}$ Unlike the earlier somatosensory component P45, LPC was maximal over central electrodes (see Figure 2). Therefore, we also tested for effects of observed touch, observed hand and their interaction over these electrodes (ipsi and contralateral FC1/2, C1/2, CP1/2, and midline $F C Z, C Z$ and $C P Z$ ), and found the same significant main effects and interactions as in the analysis of the lateral electrodes.
} 
the finding that touch evoked somewhat greater overall negativities when human hands than rubber gloves were viewed.

\section{2. Correlational analyses}

We wanted to investigate whether vicarious touch for self-related stimuli (human hands) was systematically mediated by perspective taking / mentalising and interoceptive abilities. Vicarious touch was taken to be the difference between touch and no-touch conditions where this was more or exclusively sensitive to human stimuli. This yielded two vicarious touch variables (vicarious touch for human hands over P45 and over LPC). Correlational analyses also contained eleven additional variables reflecting perspective taking and mentalising, and interoceptive sensitivity and awareness, which are described as follows.

The variable representing perspective taking was the score on the perspective-taking subscale of the IRI. This score ranged from 14 to 33 (mean: 23, SD: 4.7).

The variable representing mentalising was the average performance on all ToM questions (mean: $0.86, S D: 0.13$ ). Accuracy for ToM questions decreased with increasing level of representation / intentionality $\left(1^{\text {st }}\right.$ order mean: $1.00 ; 2^{\text {nd }}$ order mean: $0.88 ; 3^{\text {rd }}$ order mean: $0.81 ; 4^{\text {th }}$ order mean: 0.76$)$. Performance for the $4^{\text {th }}$-order non-ToM question was similar to that for the $4^{\text {th }}$-order ToM question $(0.76)$.

The average heartbeat perception score across the two instances of the heartbeat counting tasks became the variable representing interoceptive 
sensitivity. Participants' average heartbeat perception score was .76 (SD: .14), similar to typical samples in the existing literature (e.g., Pollatos et al., 2008).

The final eight variables represented interoceptive awareness in line with the eight dimensions of the MAIA. Average scores on these eight MAIA dimensions were as follows: noticing: 3.24 (SD: 1.02$)$, not-distracting: 2.00 (SD: 0.86), not-worrying: 2.52 (SD: 0.98), attention regulation: 2.99 (SD: 0.64 ), emotional awareness: 3.45 (SD: 0.86), self-regulation: $2.86(S D: 0.98)$, body listening: 2.16 (SD: 1.12), trusting: 3.65 (SD: 0.95), similar to a normative student sample (Bornemann, Herbert, Mehling, \& Singer, 2015).

We found that vicarious touch effects for human hands over both P45 and LPC positively correlated with the attention regulation dimension of the MAIA (P45: $r=.44, p=.002 ;$ LPC: $r=.39, p=.008^{2}$ ). Only the P45 statistic survived correction for multiple correlations (Benjamini \& Hochberg, 1995). In other words, individuals who scored higher on regulatory aspects of interoceptive awareness showed more evidence for vicarious representations of self-related (human hand) touch at early sensory processing stages. This relationship is depicted in Figure 4 below. Vicarious touch did not correlate with any other dimension of the MAIA $(r<.27, p>.070)$, or with interoceptive sensitivity $(r<$ $.10, p \geq .519)$. Vicarious touch was also unrelated to IRI perspective taking $(r<$ $.10, p>.528)$ and to mentalising as measured in the ToM task $(r<-.07, p \geq$ $.628)$.

Figure 4 here

\footnotetext{
${ }^{2}$ A correlation of the mirror touch effect for human hands over central electrodes where LPC was maximal (ipsi and contralateral FC1/2, C1/2, CP1/2, and midline $\mathrm{FCZ}, \mathrm{CZ}$ and CPZ) showed similar findings $(r=.37, p=$ .012).
} 


\section{Discussion}

The present study aimed to elucidate the neuronal indices of bodily selfrelatedness during vicarious touch. Self-relatedness was manipulated by investigating vicarious touch during the observation of human hands (high selfrelatedness) and rubber gloves (low self-relatedness), and measured as individual levels of interoceptive awareness, interoceptive sensitivity and mentalising abilities in perspective-taking and theory of mind tasks.

In line with our expectations, self-relatedness was associated with vicarious touch effects (significant voltage differences during touch versus no touch observations) at somatosensory component P45 (35-55 ms). More specifically, we found that vicarious touch effects were selective for human stimuli, such that significant differences between touch and no-touch conditions at P45 occurred only when observing human hands but not when observing rubber gloves. Also in line with our expectations, these effects were stronger for individuals with higher interoceptive awareness (attention-regulation dimension).

At later, more cognitive processing stages (LPC, 220-380 ms), vicarious touch was found to be sensitive to (but not selective for) human stimuli, as larger differences between touch and no-touch stimuli were present for human hands than for rubber gloves. This late vicarious touch effect for human stimuli was also tendentially related to interoceptive awareness, but this relationship was not strong enough to survive multiple-test correction. 
Vicarious touch effects for human hands (P45 or LPC) did not correlate with interoceptive sensitivity as measured by a heartbeat counting task, or with perspective taking or mentalising scores.

Our present study confirms the hypothesised tight relationship between vicarious touch and self-relatedness at P45 (Adler et al., 2016). In other words, the mirroring simulation of seen touch only occurs at P45 if the touched stimulus can be related to one's own bodily self, and this effect is larger in individuals who are more interoceptively aware. This is in line with earlier findings showing that prerequisite embodiment and the observation of highly self-related stimuli (touch on own face; Adler et al., 2016; anatomically matched touch on hands in first-person perspective; Rigato et al., 2019), are associated with vicarious touch effects over P45 specifically. P45 originates in S1 (Allison et al., 1989; 1992; Schubert et al., 2008), which is itself critically involved in vicarious touch for hands in first-person versus third-person perspectives (Schaefer et al., 2012) and in the sense of body ownership (Aspell, Palluel, \& Blanke, 2012; Otsuru, Hashizume, Nakamura, Endo, Inui, Kakigi, \& Yuge, 2014).

Unlike these early processing stages, vicarious touch effects at later processing stages (LPC) were not limited to self-relatable stimuli, although there were larger vicarious touch effects for self-related stimuli (human hands) than for non-self-related stimuli (rubber gloves). This pattern is reminiscent of our previous study (Adler et al., 2016), where we found differential vicarious touch for self and other faces over P200. A similar effect at P300 was also reported by Deschrijver et al. (2015), who demonstrated larger interactions between seen 
finger movements and felt touches on observers' fingertips when observers viewed a human hand than when they observed a wooden hand.

Modulations of P200/P300 have repeatedly been linked to self-relatedness or self-other distinction in ERP studies (e.g., Adler et al., 2016; Deschrijver et al., 2015; Longo et al., 2012; Knyazev, 2013; Zhou, Zhang, Tan \& Han, 2004). For example, larger P300 amplitudes have been shown for self-referential stimuli such as one's own name or face (see Knyazev, 2013). Given their timing, it is likely that our pattern of LPC effects reflects higher-order, cognitive representations of the self, which involve body recognition, affective categorisation and memory updating (e.g. Briggs \& Martin, 2009; Ninomiya, Onitsuka, Chen, Sato \& Tashiro, 1998; Paul, Endrass, Kathmann, \& Simon, 2016; Polich, 2007; see also Deschrijver et al., 2015), rather than sensorimotor embodiment.

However, effects at these processing stages (P200/P300) are also typically associated with congruency effects (mismatches between information from different modalities; e.g. Kok, 2001; Polich, 2007; see also Deschrijver et al., 2015). Indeed, an explanation in terms of visual-tactile mismatches would be in line with our findings of larger LPCs during the observation of no touch (vs. touch), which differs from the observer's own experience of touch on their own hand. Nonetheless, we show that these LPC differences for touch and no touch were stronger during the observation of human hands than rubber gloves, and this suggests that effects other than congruency modulate cortical processes in this time window.

In sum, while mismatch or congruency effects may contribute to ERP amplitude differences at this processing stage, the findings in their entirety can only be explained by invoking operations related to differentiation between self 
and non-self sources of stimulation. Future studies should target the influence of congruency effects on self-non-self distinction (see e.g. Deschrijver et al., 2015, for an example).

Our results demonstrate the tight relationship between mirroring processes and self-relatedness at early, implicit stages of somatosensory processing. This is further substantiated by our observed correlation between P45 vicarious touch for human hands and the attention regulation dimension of interoceptive awareness. Attention regulation requires controlled switching of one's attentional focus toward one's bodily sensations, and is therefore considered to be a key aspect of mindfulness (Hölzel, Lazar, Gard, SchumanOlivier, \& Vago, 2011; see also Bornemann et al., 2015; Mehling et al., 2012; Mirams, Poliakoff, Brown, \& Lloyd, 2013). Our study contributes to this literature by showing that individuals with better interoceptive abilities, specifically the ability to sustain and control attention to bodily signals, also have stronger vicarious representations of observed touch within somatosensory cortices. Depersonalisation, which is characterised by a disrupted relationship with the bodily self, is also marked by altered attentional processing, and it has recently been shown that these alterations occur at early cortical processing stages (Schabinger, Gillmeister, Berti, Michal, Beutel, \& Adler, 2018). This indicates that alterations in the sense of bodily self might be accompanied by alterations in the ability to selectively allocate attention to bodily or environmental stimuli. Future studies should investigate this in more detail; such endeavours might also help to further our understanding of the mechanisms underlying interoceptive awareness. 
Better interoceptive abilities might also entail a stronger sense of the difference between self and non-self sources of stimulation (self-other distinction). In line with this, we found a hint for a positive relationship between attention regulation and self-specific vicarious touch at processing stages related to self-other distinction (LPC). However, the relationship between our sense of self and vicarious representations is likely to be stronger at early sensorimotor stages of embodiment (e.g., as reflected at P45) than at later, cognitive representations of the self (e.g., as reflected at P200/P300/LPC). This is because our sense of self is primarily bodily (Blanke et al., 2015; Gallese \& Sinigaglia, 2010; Legrand, 2006; Rochat \& Striano, 2000).

We propose that our correlational findings can be explained in terms of matching incoming information to pre-existing internal representations. Individuals with a stronger sense of self may be better at mapping observed self-related (human) touch stimuli onto predictive bodily event templates. It has previously been suggested that individuals with better interoceptive abilities are less susceptible to body ownership illusions (e.g. rubber hand illusion) because such individuals have better predictive models of self-related bodily experiences (Tsakiris et al., 2011; for a recent review see Porciello, Bufalari, Minio-Palluelo, Di Pace, \& Aglioto, 2018). If incoming tactile information can be optimally accommodated, there is less reliance on visual information, and less embodiment of a rubber hand. A stronger sense of bodily self similarly explains the lower susceptibility to the rubber hand illusion in individuals with low levels of depersonalisation compared to high levels of depersonalisation (Kanayama, Sato, \& Ohira, 2009).

The links between embodiment and interoception are not altogether straightforward, however. In addition, the relationship between interoceptive 
sensitivity (accuracy) and interoceptive awareness remains to be clarified. We found that vicarious touch correlated with interoceptive awareness, but not with interoceptive sensitivity. This is in line with Mehling et al.'s (2012) finding that feelings of dissociation from one's bodily self relate to lower interoceptive awareness (specifically attention regulation), while interoceptive sensitivity does not differ between patients with depersonalisation and healthy controls (Michal et al., 2014; but see a case study by Sedeño et al., 2014). Further, mind-body training can improve individuals' interoceptive awareness, but not their interoceptive accuracy (e.g. Khalsa, Rudrauf, Damasio, Davidson, Lutz et al., 2008; but see also Filippetti \& Tsakiris, 2017). While more comprehensive studies on their differences are warranted, the evidence presently suggests that interoceptive awareness may necessitate more embodiment than interoceptive sensitivity.

In sum, the strength of vicarious representations for self-related bodily events appears to co-vary with a prerequisite attachment to one's bodily self. Our findings suggest that this relationship primarily manifests at an early, implicit stage of processing, associated with primary somatosensory component P45. This relationship may be formed at an early developmental stage, where the self can be characterised as sensorimotor-affective rather than as cognitive.

\section{1. Limitations}

Can our findings be unequivocally interpreted as genuine effects of vicarious touch? We have previously argued (Adler et al., 2016) that our paradigm minimises attentional differences between touch and no-touch conditions by presenting maximally similar attention-directing cues in both touch and no touch conditions (see also Gillmeister, 2014; Rigato et al., 2019). Since visual 
perceptual, and therefore also attentional, differences between experimental conditions can never be completely eliminated, however, it remains a possibility that diverging effects of independent unisensory visual activity contribute to our findings. Future studies could control for any residual effects of concomitant visual ERPs on somatosensory responses, for example by comparing visualtactile trials with additionally presented visual-only trials (see Sel, Galvez-Pol, \& Forster, 2014; Galvez-Pol, Calvo-Merino, Capilla, \& Forster, 2018; Arslanova, Galvez-Pol, Calvo-Merino, \& Forster, 2019). While visual ERP contamination is least likely for early component P45, it is of concern for subsequent somatosensory components (N80, P100, N140), the timing of which overlaps with visual C1 (75ms), P1 (100ms) and N1 (135-150ms) component responses to images (see Pratt, 2012).

In addition, future studies might wish to target the neural sources of P45 vicarious touch effects. In the present study, the topographic distribution of early cortical vicarious touch effect for human hands was similar to that of the P45 component, suggesting that this effect derives from the same cortical source (S1). However, our study only recorded from a limited number of scalp locations centred on somatosensory cortex, in line with our directed hypotheses for P45, and this precludes a neural source analysis. Future studies should investigate whether vicarious touch effects at P45 can be ascribed to S1 by recording from a more extensive number of scalp locations and performing neural source analyses.

Unlike previous studies (Bolognini et al., 2013, 2014; Gazzola et al., 2006; Martinez-Jauand et al., 2012; Schaefer et al., 2012), we found no evidence for a positive link between vicarious touch and individuals' perspective 
taking / mentalising abilities. Since perspective taking is a cognitive measure of empathy (e.g., Davis, 1983), it may be presumed that previously reported associations result from feedback from later, cognitive processes rather than affecting S1 embodiment directly. This complexity might mean that such links are not invariably found in measures of S1 processing. The inconsistency in findings may also represent limitations in the way that perspective taking tends to be measured (as a personality trait rather than a state of mind). Lamm et al. (2011) reported that trial by trial affective ratings predict pain-related empathic cortical activations more sensitively than trait questionnaires. Future studies might further elucidate the links between empathy and vicarious touch by employing state measures, or by investigating the relationship between perspective-taking / mentalising abilities and vicarious touch in response to more interpersonal stimuli such as faces instead of hands.

\section{2. Summary and conclusion}

This study has shown that vicarious touch and the bodily self are tightly linked at early, implicit stages of somatosensory processing. P45 vicarious touch appears to strongly depend on one's attachment to one's own body. In our previous study we found that individuals who feel detached from their own bodily self (depersonalisation) did not show the self-specific P45 vicarious touch effects seen in typical observers (Adler et al., 2016). The present study extends this finding by showing that these P45 effects only occur for stimuli that can be related to one's own body (human hands vs. rubber gloves) and are positively related to individual levels of interoceptive awareness. We also confirm that early, implicit processes are more relevant for experiencing an attachment to 
one's own body than later processes, by showing that vicarious touch at later processing stages (LPC) was less selective for the type of stimulus (human hands vs. rubber gloves). In conclusion, we suggest that the degree to which external events are experienced as self-related strongly depends on our embodiment of the self at early, implicit stages of somatosensory processing. Vicarious processes at P45 can be characterised as a neural basis for these experiences. We propose that vicarious processes and the embodied self may be representationally indistinct (linked in a common neural representation) at early, implicit somatosensory processing stages, which may have very early developmental origins in the 'pre-reflective' sense of bodily self, the emergence of which is driven by mirroring interactions with primary caregivers (Gallese \& Sinigaglia, 2010; Legrand, 2006; Rochat \& Striano, 2000). 
References:

Adler, J., Schabinger, N., Michal, M., Beutel, M. E. and Gillmeister, H. (2016). Is that me in the mirror? Depersonalisation modulates tactile mirroring mechanisms. Neuropsychologia, 85, 148-158.

https://doi.org/10.1016/j.neuropsychologia.2016.03.009

Allison, T., McCarthy, G., Wood, C. C., Williamson, P. D., \& Spencer, D. D. (1989). Human cortical potentials evoked by stimulation of the median nerve. Cytoarchitectonic areas generating long-latency activity. Journal of Neurophysiology, 62, 711-722. https://doi.org/10.1152/jn.1989.62.3.694

Allison, T., McCarthy, G., \& Wood, C. C. (1992). The relationship between human long-latency somatosensory evoked potentials recorded from the cortical surface and from the scalp. Electroencephalography and Clinical Neurophysiology, 84(4), 301-314. https://doi.org/10.1016/0168$5597(92) 90082-M$

Arslanova, I., Galvez-Pol, A., Calvo-Merino, B., \& Forster, B. (2019). Searching for bodies: ERP evidence for independent somatosensory processing during visual search for body-related information. Neuroimage, 195, 140-149. https://doi.org/10.1016/j.neuroimage.2019.03.037

Aspell, J. E., Palluel, E., \& Blanke, O. (2012). Early and late activity in somatosensory cortex reflects changes in bodily self-consciousness: An evoked potential study. Neuroscience, 216, 110-122. https://doi.org/10.1016/j.neuroscience.2012.04.039 
Banissy, M. J., \& Ward, J. (2013). Mechanisms of self-other representations and vicarious experiences of touch in mirror-touch synesthesia. Frontiers in Human Neuroscience, 7, 112. https://doi.org/10.3389/fnhum.2013.00112

Benjamini, Y., \& Hochberg, Y. (1995). Controlling the false discovery rate: a practical and powerful approach to multiple testing. Journal of the Royal Statistical Society. Series B (Methodological), 289-300. https://doi.org/10.1111/j.2517-6161.1995.tb02031.x

Blakemore, S. J., Bristow, D., Bird, G., Frith, C. and Ward, J. (2005). Somatosensory activations during the observation of touch and a case of visiontouch synaesthesia. Brain, 128, 1571-1583.

https://doi.org/10.1093/brain/awh500

Blanke, O., Slater, M. and Serino, A. (2015). Behavioral, neural, and computational principles of bodily self-consciousness. Neuron, $88,145-166$. https://doi.org/10.1016/j.neuron.2015.09.029

Bolognini, N., Rossetti, A., Convento, S., and Vallar, G. (2013). Understanding others' feelings: The role of the right primary somatosensory cortex in encoding the affective valence of others' touch. Journal of Neuroscience, 33, 4201-4205. https://doi.org/10.1523/JNEUROSCI.4498-12.2013

Bolognini, N., Rossetti, A., Fusaro, M., Vallar, G., and Miniussi, C. (2014). Sharing social touch in the primary somatosensory cortex. Current Biology, 24, 1513-1517. https://doi.org/10.1016/j.cub.2014.05.025

Bornemann, B., Herbert, B. M., Mehling, W. E., \& Singer, T. (2015). Differential changes in self-reported aspects of interoceptive awareness through 3 months of 
contemplative training. Frontiers in Psychology, 5, 1504.

https://doi.org/10.3389/fpsyg.2014.01504

Briggs, K. E., \& Martin, F. H. (2009). Affective picture processing and motivational relevance: arousal and valence effects on ERPs in an oddball task. International Journal of Psychophysiology, 72(3), 299-306.

https://doi.org/10.1016/j.ijpsycho.2009.01.009

Bufalari, I. and Ionta, S. (2013). The social and personality neuroscience of empathy for pain and touch. Frontiers in Human Neuroscience, 7, 393. https://doi.org/10.3389/fnhum.2013.00393.

Bufalari, I., Aprile, T., Avenanti, A., Di Russo, F. and Aglioti, S. M. (2007). Empathy for pain and touch in the human somatosensory cortex. Cerebral Cortex, 17, 2553-2561. https://doi.org/10.1093/cercor/bhl161

Cardini, F., Costantini, M., Galati, G., Romani, G. L., Làdavas, E. and Serino, A. (2011). Viewing one's own face being touched modulates tactile perception: an fMRI study. Journal of Cognitive Neuroscience, 23, 503-513. http://dx.doi.org/10.1037/a0031049

Cardini, F., Tajadura-Jiménez, A., Serino, A., \& Tsakiris, M. (2013). It feels like it's me: interpersonal multisensory stimulation enhances visual remapping of touch from other to self. Journal of Experimental Psychology: Human Perception and Performance, 39(3), 630. http://dx.doi.org/10.1037/a0031049

Charbonneau, J., \& O'Connor, K. (1999). Depersonalization in a non-clinical sample. Behavioural and Cognitive Psychotherapy, 27(04), 377-381. 
Craig, A. D. (2002). How do you feel? Interoception: the sense of the physiological condition of the body. Nature Reviews Neuroscience, 3(8), 655.

Davis, M. H. (1983). Measuring individual differences in empathy: Evidence for a multidimensional approach. Journal of Personality and Social Psychology, 44(1), 113. http://dx.doi.org/10.1037/0022-3514.44.1.113

Deschrijver, E., Wiersema, J. R. and Brass, M. (2015). The interaction between felt touch and tactile consequences of observed actions: an action-based somatosensory congruency paradigm. Social Cognitive and Affective Neuroscience, 11, 1162-1172. https://doi.org/10.1093/scan/nsv081 Filippetti, M. L., \& Tsakiris, M. (2017). Heartfelt embodiment: changes in bodyownership and self-identification produce distinct changes in interoceptive accuracy. Cognition, 159, 1-10. https://doi.org/10.1016/j.cognition.2016.11.002 Fonagy, P., Gergely, G., \& Target, M. (2007). The parent-infant dyad and the construction of the subjective self. Journal of Child Psychology and Psychiatry, 48(3-4), 288-328. https://doi.org/10.1111/j.1469-7610.2007.01727.x|

Fuchs, T., \& Koch, S. C. (2014). Embodied affectivity: on moving and being moved. Frontiers in Psychology, 5. https://doi.org/10.3389/fpsyg.2014.00508

Gallese, V. and Sinigaglia, C. (2010). The bodily self as power for action. Neuropsychologia, 48, 746-755.

https://doi.org/10.1016/j.neuropsychologia.2009.09.038

Galvez-Pol, A., Calvo-Merino, B., Capilla, A., \& Forster, B. (2018). Persistent recruitment of somatosensory cortex during active maintenance of hand images 
in working memory. Neuroimage, 174, 153-163.

https://doi.org/10.1016/j.neuroimage.2018.03.024

Gazzola, V., Aziz-Zadeh, L., and Keysers, C. (2006). Empathy and the somatotopic auditory mirror system in humans. Current Biology, 16, 1824-1829. https://doi.org/10.1016/j.cub.2006.07.072

Gillmeister, H., Bowling, N., Rigato, S., \& Banissy, M. J. (2017). Inter-individual differences in vicarious tactile perception: A view across the lifespan in typical and atypical populations. Multisensory Perception, 30(6).

https://doi.org/10.1163/22134808-00002543

Hölzel, B. K., Lazar, S. W., Gard, T., Schuman-Olivier, Z., Vago, D. R., \& Ott, U. (2011). How does mindfulness meditation work? Proposing mechanisms of action from a conceptual and neural perspective. Perspectives on Psychological Science, 6(6), 537-559. https://doi.org/10.1177/1745691611419671

Ishida, H., Nakajima, K., Inase, M., \& Murata, A. (2010). Shared mapping of own and others' bodies in visuotactile bimodal area of monkey parietal cortex. Journal of Cognitive Neuroscience, 22(1), 83-96.

https://doi.org/10.1162/jocn.2009.21185

Kanayama, N., Sato, A., \& Ohira, H. (2009). The role of gamma band oscillations and synchrony on rubber hand illusion and crossmodal integration. Brain and Cognition, 69(1), 19-29. https://doi.org/10.1016/j.bandc.2008.05.001

Keysers, C., Kaas, J. H. and Gazzola, V. (2010). Somatosensation in social perception. Nature Reviews Neuroscience, 11, 417-428.

https://doi.org/10.1038/nrn2833 
Khalsa, S. S., Rudrauf, D., Damasio, A. R., Davidson, R. J., Lutz, A., \& Tranel, D. (2008). Interoceptive awareness in experienced meditators. Psychophysiology, 45(4), 671-677. https://doi.org/10.1111/j.1469-8986.2008.00666.x

Kinderman, P., Dunbar, R., \& Bentall, R. P. (1998). Theory-of-mind deficits and causal attributions. British Journal of Psychology, 89(2), 191-204.

https://doi.org/10.1111/j.2044-8295.1998.tb02680.x

Knyazev, G. G. (2013). EEG correlates of self-referential processing. Frontiers in Human Neuroscience. https://doi.org/10.3389/fnhum.2013.00264

Lamm, C., Decety, J. and Singer, T. (2011). Meta-analytic evidence for common and distinct neural networks associated with directly experienced pain and empathy for pain. Neuroimage, 54, 2492-2502.

https://doi.org/10.1016/j.neuroimage.2010.10.014

Legrand, D. (2006). The bodily self: the sensori-motor roots of pre-reflective selfconsciousness. Phenomenology and the Cognitive Sciences, 5, 89-118. : https://doi.org/10.1007/s11097-005-9015-6

Longo, M. R., Musil, J. J., \& Haggard, P. (2012). Visuo-tactile integration in personal space. Journal of Cognitive Neuroscience, 24(3), 543-552.

https://doi.org/10.1162/jocn_a_00158

Martinez-Jauand, M., Gonzalez-Roldan, A.M., Munoz,M. A., Sitges, C., Cifre, I. and Montoya, P. (2012). Somatosensory activity modulation during observation of other's pain and touch. Brain Research, 1467, 48-55.

https://doi.org/10.1016/j.brainres.2012.05.055 
Markova, G., \& Legerstee, M. (2006). Contingency, imitation and affect sharing: Foundations of infants' social awareness. Developmental Psychology, 42, 132141. http://dx.doi.org/10.1037/0012-1649.42.1.132

Mehling, W. E., Price, C., Daubenmier, J. J., Acree, M., Bartmess, E. and Stewart, A. (2012). The multidimensional assessment of interoceptive awareness (MAIA). PLoS One, 7, e48230. https://doi.org/10.1371/journal.pone.0048230.

Merleau-Ponty, M. (1962). The Phenomenology of Perception. New York: Humanities Press.

Masson, M. E. (2011). A tutorial on a practical Bayesian alternative to nullhypothesis significance testing. Behavior Research Methods, 43(3), 679-690. https://doi.org/10.3758/s13428-010-0049-5

Michal, M., Reuchlein, B., Adler, J., Reiner, I., Beutel, M. E., Vögele, C., ... \& Schulz, A. (2014). Striking discrepancy of anomalous body experiences with normal interoceptive accuracy in depersonalization-derealization disorder. PLoS One, 9(2), e89823. https://doi.org/10.1371/journal.pone.0089823

Mirams, L., Poliakoff, E., Brown, R. J., \& Lloyd, D. M. (2013). Brief body-scan meditation practice improves somatosensory perceptual decision making. Consciousness and Cognition, 22(1), 348-359. https://doi.org/10.1016/j.concog.2012.07.009

Molenberghs, P., Cunnington, R. and Mattingley, J. B. (2012). Brain regions with mirror properties: a meta-analysis of 125 human fMRI studies. Neuroscience \& Biobehavioral Reviews, 36, 341-349. https://doi.org/10.1016/j.neubiorev.2011.07.004 
Ninomiya, H., Onitsuka, T., Chen, C.H., Sato, E., \& Tashiro, N. (1998). P300 in response to the subject's own face. Psychiatry and Clinical Neurosciences, 52, 519-522. https://doi.org/10.1046/j.1440-1819.1998.00445.x

Otsuru, N., Hashizume, A., Nakamura, D., Endo, Y., Inui, K., Kakigi, R. and Yuge, L. (2014). Sensory incongruence leading to hand disownership modulates somatosensory cortical processing. Cortex, 58, 1-8.

https://doi.org/10.1016/j.cortex.2014.05.005

Paul, S., Endrass, T., Kathmann, N., \& Simon, D. (2016). Adapting another person's affective state modulates brain potentials to unpleasant pictures. Biological Psychology, 120, 81-87. https://doi.org/10.1016/j.biopsycho.2016.08.010

Polich, J. (2007). Updating P300: an integrative theory of P3a and P3b. Clinical Neurophysiology, 118(10), 2128-2148.

https://doi.org/10.1016/j.clinph.2007.04.019

Pollatos, O., Kurz, A. L., Albrecht, J., Schreder, T., Kleemann, A. M., Schöpf, V., ... \& Schandry, R. (2008). Reduced perception of bodily signals in anorexia nervosa. Eating Behaviors, 9(4), 381-388.

https://doi.org/10.1016/j.eatbeh.2008.02.001

Porciello, G., Bufalari, I., Minio-Paluello, I., Di Pace, E., \& Aglioti, S. M. (2018). The 'Enfacement' illusion: A window on the plasticity of the self. Cortex, 104. 261-275. https://doi.org/10.1016/j.cortex.2018.01.007

Pratt, H. (2011). Sensory ERP components. The Oxford handbook of eventrelated potential components, pp. 89-114. 
Rigato, S., Bremner, A., Gillmeister, H., \& Banissy, M. (2019). Interpersonal representations of touch in the somatosensory cortex are modulated by perspective. Biological Psychology, 146.

https://doi.org/10.1016/j.biopsycho.2019.107719.

Rochat, P. and Striano, T. (2000). Perceived self in infancy. Infant Behaviour and Development, 23, 513-530. https://doi.org/10.1016/S0163-6383(01)00055-8

Rutherford, M. D. (2004). The effect of social role on theory of mind reasoning. British Journal of Psychology, 95(1), 91-103.

https://doi.org/10.1348/000712604322779488

Schabinger, N., Gillmeister, H., Berti, S., Michal, M., Beutel, M. E., \& Adler, J. (2018). Detached and distracted: ERP correlates of altered attentional function in depersonalisation. Biological Psychology, 134, 64-71. https://doi.org/10.1016/j.biopsycho.2018.02.014

Schaefer, M., Xu, B., Flor, H. and Cohen, L. G. (2009). Effects of different viewing perspectives on somatosensory activations during observation of touch. Human Brain Mapping, 30, 2722-2730. https://doi.org/10.1002/hbm.20701

Schaefer, M., Heinze, H. J. and Rotte, M. (2012). Embodied empathy for tactile events: interindividual differences and vicarious somatosensory responses during touch observation. Neuroimage, 60, 952-957. https://doi.org/10.1016/j.neuroimage.2012.01.112

Schandry, R. (1981). Heart beat perception and emotional experience. Psychophysiology, 18(4), 483-488. https://doi.org/10.1111/j.14698986.1981.tb02486.x 
Schubert, R., Ritter, P., Wustenberg, T., Preuschhof, C., Curio, G., Sommer, W., et al. (2008). Spatial attention related SEP amplitude modulations covary with BOLD signal in S1 - a simultaneous EEG-fMRI study. Cerebral Cortex, 18, 2686-2700. https://doi.org/10.1093/cercor/bhn029

Sedeño, L., Couto, B., Melloni, M., Canales-Johnson, A., Yoris, A., Baez, S., ... \& Kichic, R. (2014). How do you feel when you can't feel your body? Interoception, functional connectivity and emotional processing in depersonalizationderealization disorder. PloS One, 9(6), e98769. https://doi.org/10.1371/journal.pone.0098769

Sel, A., Forster, B., \& Calvo-Merino, B. (2014). The emotional homunculus: ERP evidence for independent somatosensory responses during facial emotional processing. Journal of Neuroscience, 34(9), 3263-3267. https://doi.org/10.1523/JNEUROSCI.0106-13.2014

Serino, A., Pizzoferrato, F. and Làdavas, E. (2008). Viewing a face especially one's own face being touched enhances tactile perception on the face. Psychological Science, 19, 434-438. https://doi.org/10.1111/j.1467$9280.2008 .02105 . x$

Serino, A., Giovagnoli, G. and Làdavas, E. (2009). I feel what you feel if you are similar to me. Plos One 4(3), e4930.

https://doi.org/10.1371/journal.pone.0004930

Sierra, M., \& Berrios, G. E. (2000). The Cambridge Depersonalisation Scale: a new instrument for the measurement of depersonalisation. Psychiatry Research, 93(2), 153-164. https://doi.org/10.1016/S0165-1781(00)00100-1 
Sierra, M., Baker, D., Medford, N., \& David, A. S. (2005). Unpacking the depersonalization syndrome: an exploratory factor analysis on the Cambridge Depersonalization Scale. Psychological Medicine, 35(10), 1523-1532. https://doi.org/10.1017/S0033291705005325

Sierra, M., \& David, A. S. (2011). Depersonalization: a selective impairment of self-awareness. Consciousness and Cognition, 20(1), 99-108. https://doi.org/10.1016/j.concog.2010.10.018

Simeon, D. (2004). Depersonalisation disorder - A contemporary overview. CNS Drugs, 18(6), 343-354. https://doi.org/10.2165/00023210-200418060-00002 Stern, D. N. (1995). Self-other differentiation in the domain of intimate socioaffective interaction: Some considerations. In P. Rochat (Ed.), The self in infancy: Theory and research (pp. 419-429). Amsterdam: Elsevier Science.

Trueman, D. (1984). Depersonalization in a Nonclinical Population. Journal of Psychology, 116(1), 107-112. https://doi.org/10.1080/00223980.1984.9923624 Tsakiris, M., Tajadura-Jiménez, A. and Costantini, M. (2011). Just a heartbeat away from one's body: interoceptive sensitivity predicts malleability of bodyrepresentations. Proceedings of the Royal Society London B: Biological Sciences, 278(1717), 2470-2476. https://doi.org/10.1098/rspb.2010.2547

Wittkamp, M. F., Bertsch, K., Vögele, C., \& Schulz, A. (2018). A latent state-trait analysis of interoceptive accuracy. Psychophysiology, 55(6), e13055. https://doi.org/10.1111/psyp.13055

Zhou, B., Zhang, J. X., Tan, L. H., \& Han, S. (2004). Spatial congruence in working memory: an ERP study. NeuroReport, 15(18), 2795-2799. 
Bodily self-relatedness in vicarious touch 
Figure legends

Figure 1. Examples of touch and no touch trials for human hand and rubber glove conditions, showing stimulus timings.

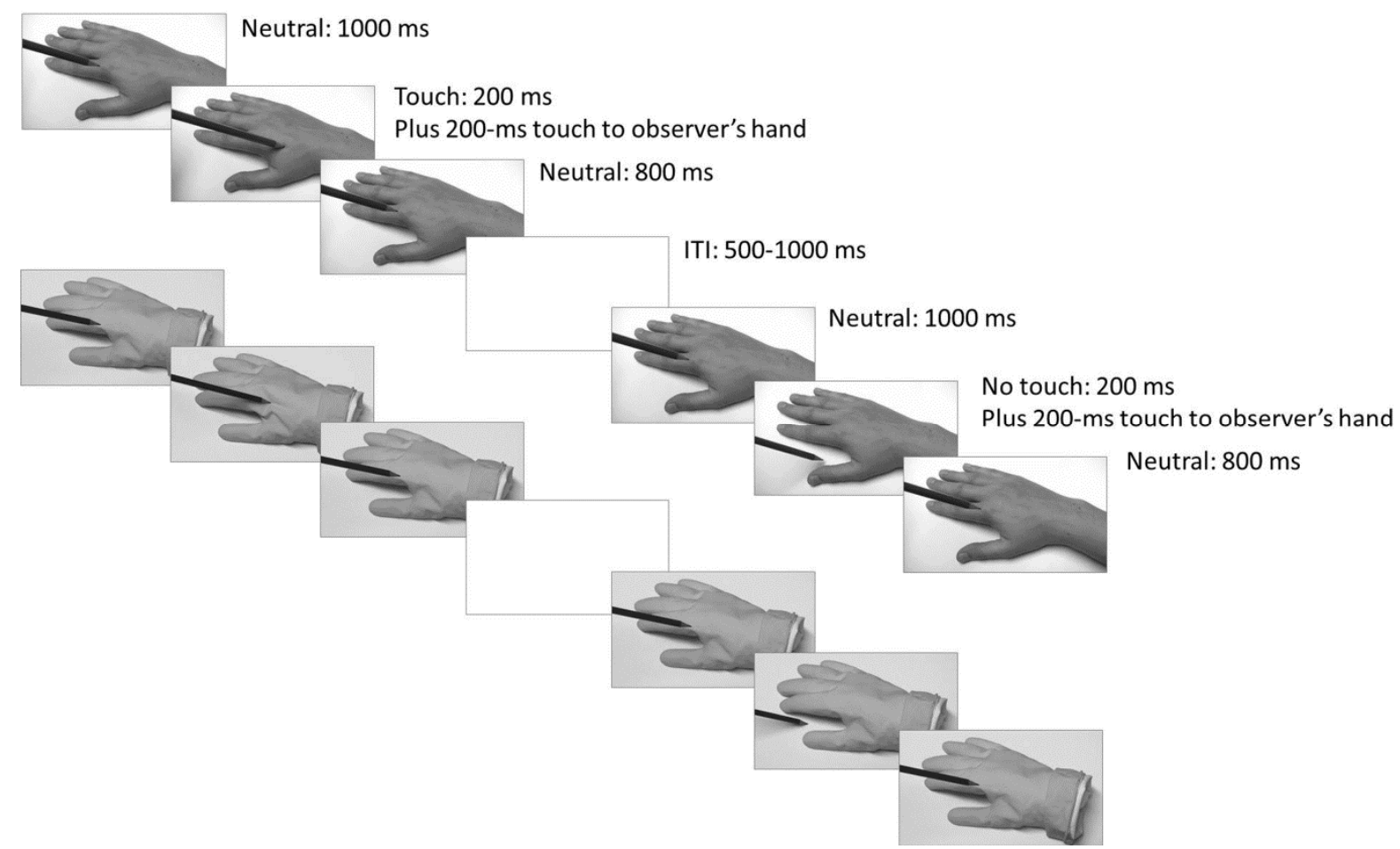

Figure 2. Topographic maps of average voltage distributions with contralateral electrodes displayed in left hemispheres, ipsilateral in right hemispheres. Electrodes entered into analyses on the basis of the presence and size of components are marked in white. Top panel shows scalp distributions of maximum positivities in P45 (left panel) and LPC (right panel) time windows (collapsed over all conditions). Middle and bottom panels show scalp distributions of maximum differences between touch and no-touch trials in the same time windows for human hand (middle panel) and rubber glove (bottom panel) conditions. For P45, difference waves were calculated by subtracting notouch from touch waveforms; for LPC, they were calculated by subtracting touch from no-touch waveforms (see Figure 3). 


\section{P45 (35-55ms)}
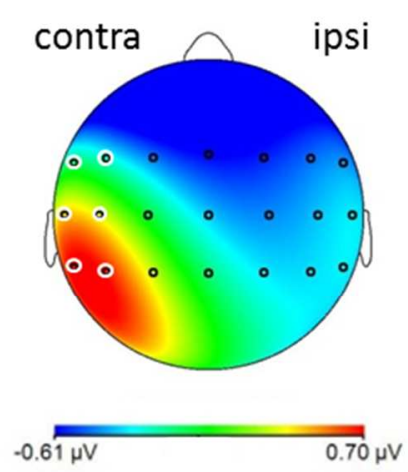

\section{LPC (220-380ms)}
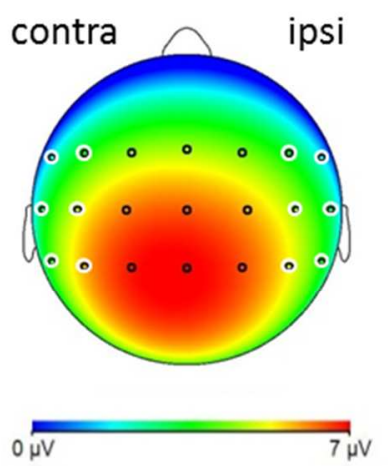

Difference wave (touch vs. no touch)
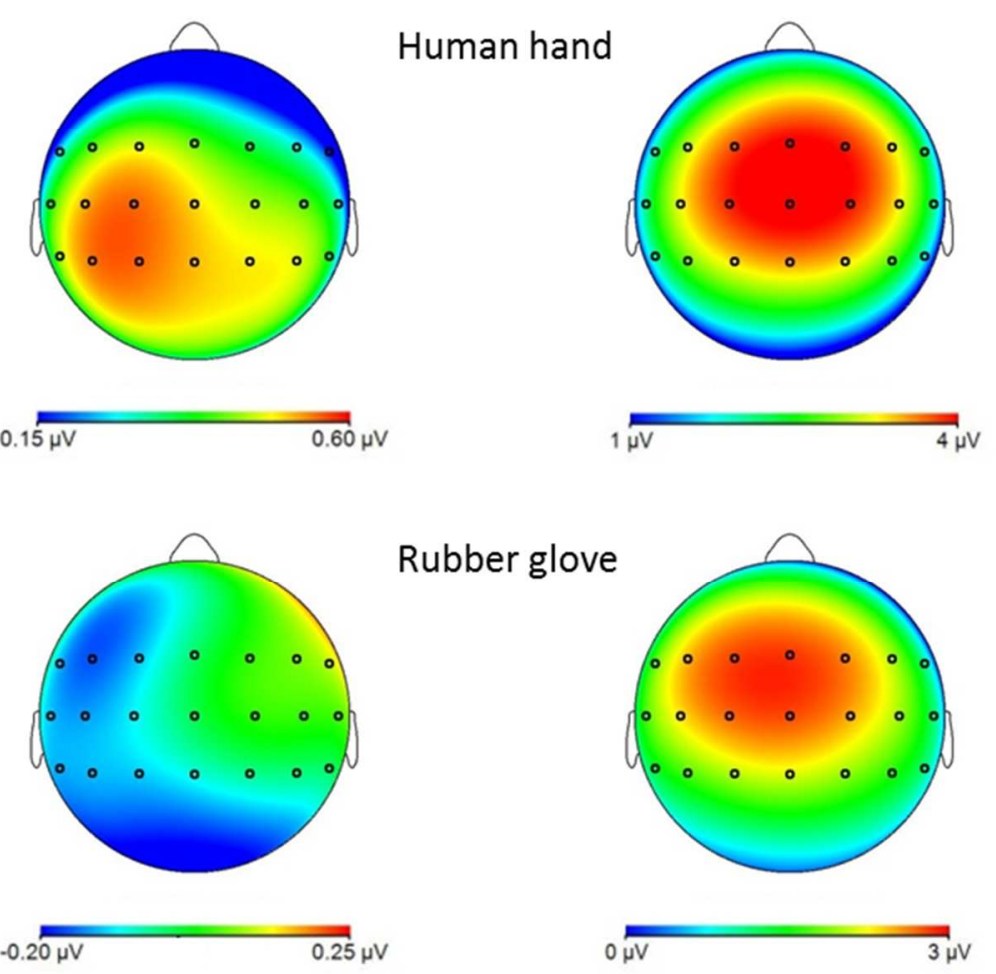

Figure 3. Somatosensory ERPs in response to touch on participants' hands over a contralateral (top panels) or ipsilateral (bottom panel) cluster of electrodes (average of $\mathrm{FC} 5 / 6, \mathrm{FC} 3 / 4, \mathrm{C} 5 / 6, \mathrm{C} 3 / 4, \mathrm{CP} 5 / 6, \mathrm{CP} 3 / 4$ ). Somatosensory component P45 and the LPC are indicated. Asterisks denote significant differences between conditions in which touch (black lines) versus no touch (grey lines) was viewed on a human hand (left panels) or rubber glove (right panels). 

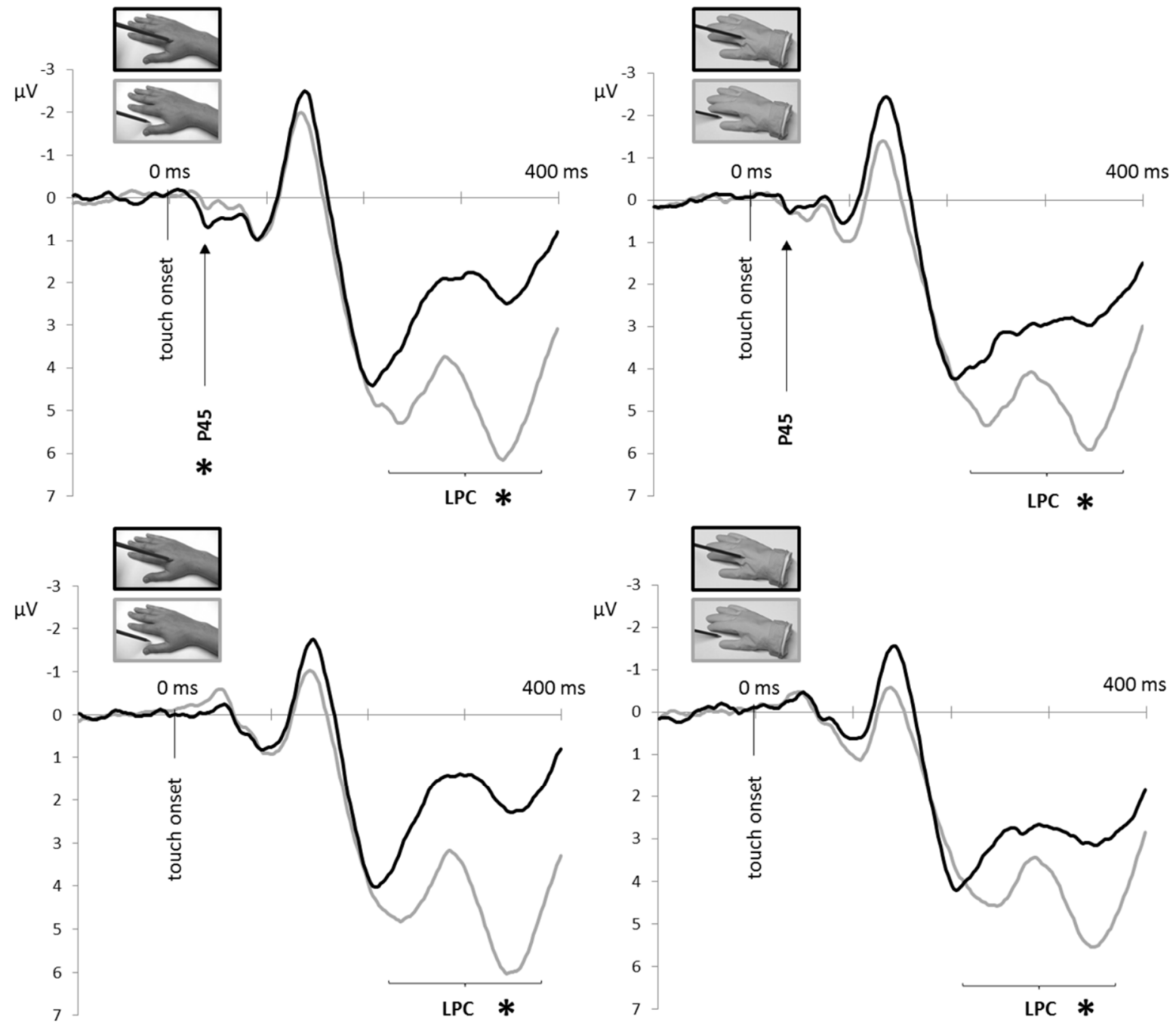

Figure 4. Scatterplot showing the relationship between individual levels of interoceptive awareness (attention regulation dimension) and vicarious touch for human hands over P45 (P45 amplitude in touch trials minus P45 amplitude in no-touch trials). The central line represents the linear regression line that best fits the data points (least squares method), while the outer lines represent the $95 \%$ confidence interval. 


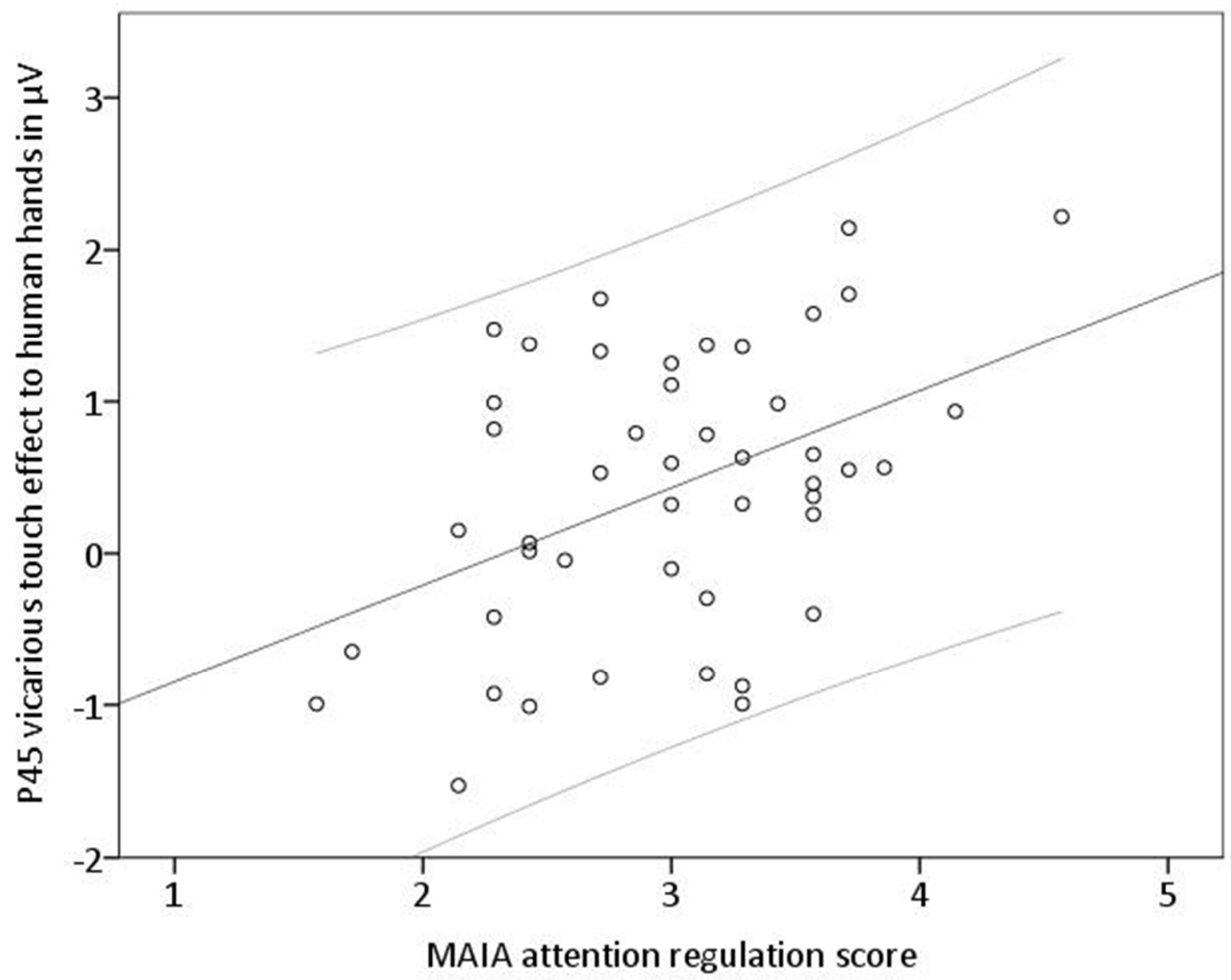

